\title{
Prostatectomy using different lasers for the treatment of benign prostate hyperplasia in aging males
}

This article was published in the following Dove Press journal:

Clinical Interventions in Aging

5 November 2013

Number of times this article has been viewed

\author{
Wei-Chang Lee ${ }^{1, *}$ \\ Yu-Hsiang Lin ${ }^{1, *}$ \\ Chen-Pang Hou' \\ Phei-Lang Chang' \\ Chien-Lun Chen' \\ Horng-Heng Juang ${ }^{2}$ \\ Ke-Hung Tsui'
}

'Department of Urology, Chang Gung Memorial Hospital-Linko and Chang

Gung University, College of Medicine,

Taiwan, ${ }^{2}$ Department of Anatomy,

College of Medicine, Chang Gung

University, Kweishan-Shan, Taoyuan,

Taiwan, Republic of China

*These authors contributed equally to this work
Correspondence: Ke-Hung Tsui Department of Urology, Chang Gung Memory Hospital-Linko, Chang Gung University, 5 Fu-Shing Street Kwei-Shan, Taoyuan 333, Taiwan, Republic of China Tel +886 3328 I 200 ext 2। 37

Fax +886321I 8II2

Email khtsui@yahoo.com
Purpose: Endoscopic lasers have become a treatment option for benign prostate hyperplasia (BPH). The study reported here sought to elucidate the benefits and drawbacks of different laser systems in the treatment of patients with BPH.

Methods: The study enrolled 741 patients diagnosed with lower urinary tract symptoms secondary to BPH during the period January 2005 to December 2011. The techniques used in the study were photoselective vaporization of the prostate, thulium laser prostatectomy, and diode laser prostatectomy. Patients were assigned to one of three groups according to the type of laser treatment they received. Outcomes were evaluated using the International Prostate Symptom Score (IPSS), quality of life, maximal urinary flow rate, post-voiding residual urine volume, and prostate-specific antigen (PSA) level.

Results: The baseline characteristics of patients who received diode laser prostatectomy show a significant elevated risk and high American Society of Anesthesiology score $(P=0.001)$. Operative time and catheter removal time differed significantly between the three groups $(P=0.001)$. No cases were converted to transurethral resection of the prostate intraoperatively due to bleeding $(P=0.142)$. Among the three groups, there were no significant differences in maximal flow rate, lower post-void residual urine, and postoperative PSA level during the entire follow-up period $(P<0.05)$. Further, no significant differences in postoperative IPSS, quality of life, or bladder neck contracture $(P=0.23)$ were observed. However, a significant difference was observed with regard to prolonged use of Foley catheters and prolonged hospital stay among patients in the diode laser group $(P=0.001)$.

Conclusion: Laser prostatectomies are effective in dealing with lower urinary tract symptoms. Early subjective functional results (maximal flow rate, IPSS, and post-void residual urine) appeared the same as those obtained following laser prostatectomy. Thus, it appears that lasers are safe and effective as long as the patients are carefully selected for treatment.

Keywords: prostate gland, laser prostatectomy, diode laser, thulium laser, photoselective vaporization of the prostate

\section{Introduction}

Transurethral resection of the prostate (TURP) is generally considered the gold standard for the surgical treatment of benign prostate hyperplasia (BPH). ${ }^{1}$ However, laser technology has also been used to treat lower urinary tract symptoms (LUTS) secondary to BPH for more than 15 years. ${ }^{2,3}$ Increasingly, laser therapy is being considered for the surgical management of BPH of any size, as an alternative to TURP. ${ }^{3,4}$ Several different initial laser techniques have been introduced to make prostatectomy procedures safer and more effective. Such techniques include use of high-powered 120 W (GreenLight ${ }^{\text {TM }}$ HPS $^{\circledR}$; American Medical Systems, Minnetonka, MN, USA), 
thulium (Tm), diode, holmium, and vela lasers. Techniques consist of coagulation (photoselective vaporization of the prostate $[\mathrm{PVP}]$ ), vaporization (PVP and diode), resection, and enucleation (Tm), depending on the wavelength, power, and type of laser emission. These methods have proven safe among patients with a high risk of bleeding (anticoagulant users, those with a tendency for bleeding, or those with an American Society of Anesthesiology [ASA] score >3)., ${ }^{5,6}$

Laser prostatectomy is also superior to TURP with regard to reducing blood transfusions and the length of hospital stay; however, it results in a higher reoperation rate. ${ }^{5,7}$ Advanced laser techniques have been proposed as an alternative to TURP; however, current lasers and laser techniques differ considerably in terms of handling and their interaction with tissue. The study reported here aimed to elucidate the differences between laser systems and help urologists critically evaluate the effectiveness of each system in the treatment of LUTS due to BPH. Our results provide a valuable guide to assist urologists in selecting the most suitable laser option for each patient.

\section{Materials and methods}

The study enrolled 741 patients between January 2005 and December 2011 at Chang Gung Memorial Hospital-LinKo. Inclusion criterion was LUTS secondary to BPH. Patients with postoperative prostate pathology showing malignancies were excluded (24 patients, 3.2\%). Surgical treatment was initiated according to BPH guidelines provided by the European Association of Urology. ${ }^{8}$ Laser surgery in each group was performed or supervised by a single surgeon who possessed expertise in laser therapy.

Recorded parameters included age, history of antiplatelet or anticoagulant drugs, International Prostatic Symptom Score (IPSS), digital rectal exam, prostate-specific antigen (PSA) level, prostate volume, and transitional-zone volume determined by transrectal ultrasound. In addition, uroflow studies were conducted at 3, 6, 12, and 24 months before and after the operation. Postoperative evaluation focused on peak-flow rate (Qmax) and post-voiding residual urine, the occurrence of acute urine retention, and whether a Foley catheter was inserted prior to the operation.
We also recorded ASA score, duration of operation, length of catheterization, length of hospital stay, as well as intraoperative, early, and late complications. Intraoperative complications included blood loss requiring transfusion and TURP syndrome. Early operative complications (occurring within 30 days of surgery) included acute urine retention requiring re-catheterization, hematuria requiring surgical intervention, and urosepsis. Late complications included bladder neck contracture or a urethral stricture that required secondary surgical intervention. Follow-up evaluations were conducted in the outpatient department of the clinic.

\section{Characteristics of the lasers used}

PVP is performed using a high-powered $120 \mathrm{~W}$ (GreenLight HPS) laser system and a side-firing AddStat ${ }^{\mathrm{TM}}$ Fiber (American Medical Systems) with a core diameter of $600 \mathrm{~mm}$. Power settings were increased from 100 to $120 \mathrm{~W}$ after tissue was found to become resistant to vaporization. ${ }^{4}$

Conversely, the Tm laser operates at a wavelength of $2,000 \mathrm{~nm}$ and is delivered as a continuous wave. Tm lasers enable the complete absorption of laser energy in water, and due to their slightly shorter wavelength, the depth of penetration is only $0.25 \mathrm{~mm}$. This leads to rapid vaporization and resection of tissue. Nonetheless, Tm lasers are suitable for transurethral vaporization, resection, or enucleation of the prostate.

Diode lasers use a special diode to generate energy. The operating wavelength of $980 \mathrm{~nm}$ is near the infrared electromagnetic spectrum, and is therefore easily absorbed by water and hemoglobin. This results in good hemostatic properties and tissue vaporization performance.

Table 1 summarizes the main characteristics of the lasers discussed here.

\section{Statistical analysis}

The mean \pm standard deviation of all continuous measures and scores was recorded at baseline and during all follow-up visits. Statistical analysis was performed using analysis of variance or Student's $t$-test to produce continuous data approximating normal distribution. Continuous variables were compared between treatment groups using a second

Table I Main characteristics of the different laser techniques

\begin{tabular}{lllll}
\hline Laser technique & WL, $\mathbf{n m}$ & Chromophore(s) & Depth, $\mathbf{m m}$ & Application \\
\hline PVP & 532 & Hemoglobin & 0.80 & Tissue vaporization \\
Tm laser prostatectomy & 2,000 & Water & 0.25 & Tissue vaporization, resection, enucleation \\
Diode laser prostatectomy & 980 & Water, hemoglobin & $>0.50$ & Tissue vaporization \\
\hline
\end{tabular}

Abbreviations: PVP, photoselective vaporization of prostate; Tm, thulium; WL, wavelength. 
Student's $t$-test, with $P$-values $<0.05$ considered significant. Multivariate logistic regression analysis was performed to assess the impact of selected factors on postoperative outcome parameters, with $P$-values $<0.05$ considered statistically significant. All analyses were performed using commercially available software.

\section{Results}

Baseline patient characteristics are listed in Table 2. The diode laser vaporization group included a greater number of anticoagulant users and patients with an ASA score $>3$, higher PSA level, prostate volume, and catheterization prior to the operation $(P=0.01)$. Most patients taking warfarin and heparin who had a prostate weighing $<60 \mathrm{~g}$ underwent PVP treatment and most patients taking these same anticoagulants with a prostate weighing $>60 \mathrm{~g}$ underwent treatment with a diode laser. The remaining patients were assigned to Tm enucleation laser therapy. Additionally, the vast majority of patients who were given antiplatelet therapy (aspirin and/or clopidogrel) underwent diode laser therapy $(P=0.001)$.

Urinary retention rates were as follows: GreenLight HPS group, 31.1\%; Tm group, 38\%; and diode group, $48.6 \%$. The average length of hospital stay was $2.5 \pm 1.4$ days for the HPS group, $2.5+1.0$ days for the Tm group, and $3.1+1.2$ days for the diode group $(P<0.001)$.

Table 2 Baseline characteristics of patients in the three groups

\begin{tabular}{|c|c|c|c|c|}
\hline $\begin{array}{l}\text { Characteristics } \\
\text { (mean } \pm \text { standard } \\
\text { deviation) }\end{array}$ & $\begin{array}{l}\text { PVP } \\
(n=402)\end{array}$ & $\begin{array}{l}\text { Thulium } \\
(n=245)\end{array}$ & $\begin{array}{l}\text { Diode } \\
(n=70)\end{array}$ & $P$ \\
\hline Age & $71.3 \pm 9.6$ & $70.0 \pm 8.1$ & $72.7 \pm 9.4$ & 0.049 \\
\hline Diabetes mellitus & 64 (I5.9) & $38(15.5)$ & $12(17.1)$ & 0.947 \\
\hline Hypertension & $202(50.2)$ & $104(42.4)$ & 37 (52.9) & 0.106 \\
\hline History of TURP & $18(4.5)$ & $6(2.4)$ & I (I.4) & 0.242 \\
\hline Aspirin & $82(20.4)$ & $30(12.2)$ & $13(18.6)$ & 0.029 \\
\hline Warfarin & $8(2.0)$ & $4(1.6)$ & $12(17.1)$ & $<\mathbf{0 . 0 0 1}$ \\
\hline Thrombocytopenia & $37(9.2)$ & $13(5.3)$ & $6(8.6)$ & 0.195 \\
\hline ASA score $=3$ or 4 & 157 (39) & $91(37.1)$ & $47(67.1)$ & $<0.001$ \\
\hline IPSS & $26.0 \pm 3.8$ & $25.5 \pm 4.1$ & $26.0 \pm 3.6$ & 0.197 \\
\hline PSA & $6.1 \pm 6.0$ & $8.0 \pm 6.1$ & $8.5 \pm 6.9$ & $<\mathbf{0 . 0 0 1}$ \\
\hline Free PSA, \% & $25.3 \pm 11.2$ & $23.7 \pm 8.3$ & $25.2 \pm 9.7$ & 0.554 \\
\hline Volume of prostate & $51.7 \pm 20.9$ & $68.4 \pm 26.3$ & $73.7 \pm 37.8$ & $<0.001$ \\
\hline T-volume & $25.7 \pm 14.9$ & $33.6 \pm 18.3$ & $37.6 \pm 24.5$ & $<0.001$ \\
\hline $\begin{array}{l}\text { Catheterization } \\
\text { before op }\end{array}$ & $125(3 \mathrm{I} . \mathrm{I})$ & $93(38.0)$ & $34(48.6)$ & 0.010 \\
\hline Op with stone & $21(6.8)$ & $29(23.6)$ & I (3.7) & 0.010 \\
\hline Op time, minutes & $106.9 \pm 39.9$ & $97.8 \pm 39.0$ & $98.6 \pm 31.4$ & 0.009 \\
\hline
\end{tabular}

Note: Values in bold text, $P<0.05$ is significant difference.

Abbreviations: ASA, American Society of Anesthesiology; IPSS, International Prostatic Symptom Score; PSA, prostate-specific antigen; PVP, photoselective vaporization of prostate; Op, operation; TURP, transurethral resection of prostate; T-volume, transitional zone of prostate volume.
Table 3 presents the intraoperative, early, and late postoperative complications and outcomes for patients in the three groups. With the exception of re-catheterization, no significant difference in the rate of complications was observed between the three groups. Despite the high recatheterization rate in the diode laser group $(P=0.001)$, all of these patients showed improvements after Foley training and medications. A total of 51 patients $(7.1 \%)$ presented with urinary retention and were administered urethral catheters for a mean of 7.6 days. Patients in the diode laser group were at higher risk for bleeding; however, the blood transfusion rate and check bleeding rate were not significantly higher than those observed in the other groups $(P>0.05)$. All groups (Figure 1) showed significant improvements in terms of postvoid residual urine volume, Qmax, and PSA level. The PSA levels are dramatically decreased after surgery, also indicated improvements for at least 1 year postoperatively.

Meta-analysis provided valuable information on the predictors of overall complications. Logistic regression results revealed that most cases of induced comorbidity presented significant differences in prostate volume (hazard ratio $[\mathrm{HR}]=1.03 ; 95 \%$ confidence interval $[\mathrm{CI}]$ : 1.01-1.05; $P=0.003)$ and catheterization before the operation $(\mathrm{HR}=2.92$, 95\% CI: $1.16-7.36 ; P=0.023)$. Other factors, including age, incidence of diabetes mellitus, hypertension, and thrombocytopenia, as well as medical record post-TURP, IPSS score, PSA level, and operative time, were not associated with complications in any of the three laser groups. In the Tm group, catheterization before the operation presented a higher overall complication rate than that among patients who did

Table 3 Intraoperative, early, and late postoperative complications and outcomes in patients in the three groups

\begin{tabular}{|c|c|c|c|c|}
\hline $\begin{array}{l}\text { Mean } \pm \text { SD (median) } \\
\text { or } n(\%) \text { variable }\end{array}$ & $\begin{array}{l}\text { PVP } \\
(n=402)\end{array}$ & $\begin{array}{l}\text { Thulium } \\
(n=245)\end{array}$ & $\begin{array}{l}\text { Diode } \\
(n=70)\end{array}$ & $\boldsymbol{P}$ \\
\hline Follow-up (months) & $38.7(39)$ & $25.2(23)$ & $24.4(20)$ & \\
\hline \multicolumn{5}{|c|}{ Intraoperative complications } \\
\hline Blood transfusion & $\mathrm{I}(0.2)$ & $0(0.0)$ & $0(0.0)$ & 1.000 \\
\hline TURP syndrome & $0(0)$ & $0(0)$ & $0(0)$ & 1.000 \\
\hline \multicolumn{5}{|c|}{ Early ( $<30$ days) postoperative complications } \\
\hline Check bleeding & $3(0.7)$ & $5(2.0)$ & $2(2.9)$ & 0.142 \\
\hline Re-catheterization & $30(7.5)$ & $9(3.7)$ & $12(17.1)$ & 0.001 \\
\hline Urosepsis & $8(2.0)$ & $4(1.6)$ & I (I.4) & 1.000 \\
\hline \multicolumn{5}{|c|}{ Late $(>30$ days) postoperative complications } \\
\hline $\begin{array}{l}\text { Reop: TURP } \\
\text { or TUR-BN }\end{array}$ & $20(5.0)$ & $6(2.4)$ & $4(5.7)$ & 0.237 \\
\hline $\begin{array}{l}\text { Duration of } \\
\text { hospitalization (days) }\end{array}$ & $3.5 \pm 1.4$ & $3.5 \pm 1.0$ & $4.1 \pm 1.2$ & $<0.001$ \\
\hline
\end{tabular}

Abbreviations: Reop, reoperation; PVP, photoselective vaporization of prostate; SD, standard deviation; TUR-BN, transurethral resection of bladder neck; TURP, transurethral resection of prostate. 

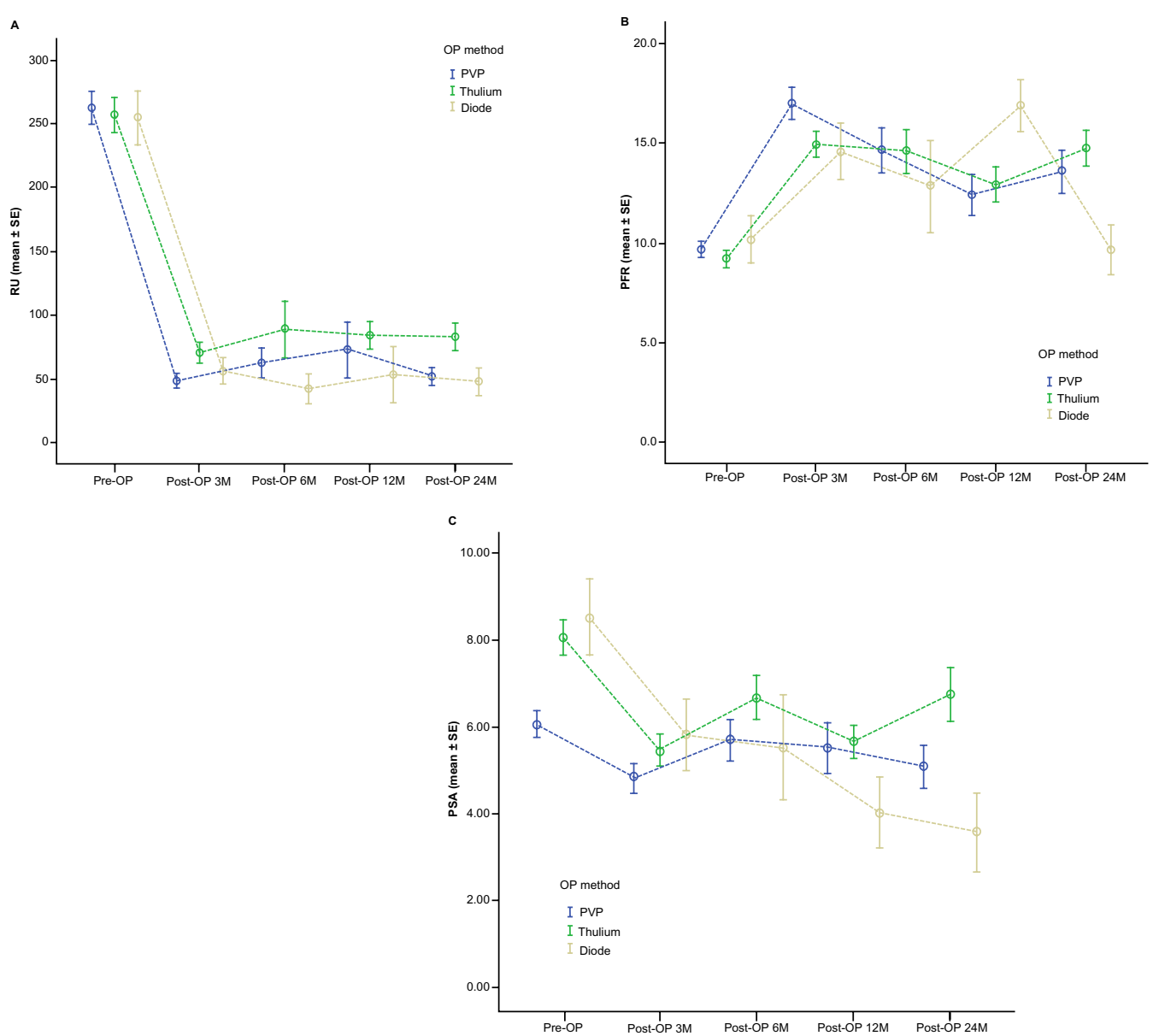

Figure I Logistic regression analysis for three types of laser prostatectomy: predicted (A) post-void residual urine volume, (B) peak-flow rate (PFR), and (C) prostatespecific antigen (PSA) level curves.

Note: A significant improvement was observed in terms of post-voiding residual urine volume, peak-flow rate, and PSA level, compared with preoperative levels $(P<0.05)$. Abbreviations: M, months; OP, operation; PVP, photoselective vaporization of prostate; RU, residual urine; SE, standard error.

not undergo catheterization $(P=0.023)$. Additionally, in the Tm group, a $1 \mathrm{~g}$ increase in prostate volume did not present a significant increase in complication rates, but a prostate volume exceeding $100 \mathrm{~g}$ was associated with a significantly higher surgical morbidity rate (Table 4).

\section{Discussion}

Laser prostatectomy for the treatment of LUTS provides outcomes and lower complication rates at least equal to those obtained with TURP. ${ }^{7}$ However, the idea that TURP should be replaced by laser therapy as the gold standard is still not widely accepted due to the lack of studies on a large number of cases.

We found that laser prostatectomy resulted in relatively low rates of intraoperative and perioperative complications. We also observed that patients taking aspirin or warfarin had a higher rate of perioperative bleeding compared with those who did not take these drugs; however, withholding these medications resulted in increased rates of cardiovascular
Table 4 Logistic regression analysis to predict overall morbidities of laser prostatectomy

\begin{tabular}{|c|c|c|c|c|c|c|}
\hline \multirow[t]{2}{*}{$\begin{array}{l}\text { Op method } \\
\text { Characteristic }\end{array}$} & \multicolumn{2}{|c|}{$\begin{array}{l}\text { PVP } \\
(n=402)\end{array}$} & \multicolumn{2}{|c|}{$\begin{array}{l}\text { Thulium } \\
(n=245)\end{array}$} & \multicolumn{2}{|l|}{$\begin{array}{l}\text { Diode } \\
(n=70)\end{array}$} \\
\hline & $\bar{P}$ & $\overline{\text { OR }}$ & $\bar{P}$ & OR & $\bar{P}$ & OR \\
\hline Age & 0.713 & 0.99 & 0.654 & 1.01 & 0.659 & 0.99 \\
\hline Diabetes mellitus & 401 & 1.38 & 186 & 0.25 & 214 & 2.40 \\
\hline Hypertension & 0.734 & 0.90 & 0.968 & 1.02 & .405 & 0.60 \\
\hline History of TURP & 0.207 & 2.10 & 1.000 & $1.295^{\mathrm{a}}$ & 1.000 & $4.00^{\mathrm{a}}$ \\
\hline Thror & 0.407 & 0.60 & 0.605 & $0.562^{\mathrm{a}}$ & 0.402 & 2.17 \\
\hline IPSS & 0.545 & 1.02 & 0.982 & 1.00 & 0.855 & 1.02 \\
\hline $\begin{array}{l}\text { Prostate-specific } \\
\text { antigen }\end{array}$ & 0.740 & 0.99 & 0.083 & 1.06 & .297 & 1.05 \\
\hline $\begin{array}{l}\text { Free prostate- } \\
\text { specific antigen }\end{array}$ & 0.940 & 1.00 & 0.511 & 1.03 & 0.554 & 1.04 \\
\hline Volume & 0.131 & 1.01 & $0.003^{b}$ & $1.03^{\mathrm{b}}$ & .089 & 1.02 \\
\hline T-volume & 0.798 & 1.00 & 0.504 & 1.01 & 0.230 & 1.02 \\
\hline $\begin{array}{l}\text { Catheterization } \\
\text { before op }\end{array}$ & 0.078 & 1.73 & $0.023^{b}$ & $2.92^{\mathrm{b}}$ & $0.064^{c}$ & $3.33^{\mathrm{c}}$ \\
\hline Surgical time & 0.257 & 1.00 & 0.738 & 1.00 & 0.480 & 1.01 \\
\hline
\end{tabular}

Notes: ${ }^{a}$ Kruskal-Wallis test; ${ }^{b}$ Analysis of variance test; 'chi-square test.

Abbreviations: IPSS, International Prostatic Symptom Score; PVP, photoselective vaporization of prostate; op, operation; OR, odds ratio; TURP, transurethral resection of prostate; T-volume, transitional zone of prostate volume. 
and cerebrovascular complications. ${ }^{6,8}$ Nonetheless, laser prostatectomy was found to be a useful alternative to TURP in treating patients taking antiplatelet and anticoagulation drugs. ${ }^{9-11}$

Patients undergoing diode laser therapy did not require postoperative blood transfusions. The re-catheterization rate was between $4.3 \%$ and $20.0 \%{ }^{12,13}$ Patients in the diode laser group had a re-catheterization rate of approximately $17 \%$. Diode lasers are recommended for patients at high risk of bleeding. Rieken et al reported that among patients who underwent diode laser treatment, $9.6 \%$ of those with bladder neck obstruction required reoperation, compared with $3.6 \%$ among those who underwent TURP. ${ }^{14}$ In addition, a urethral stricture developed in 5.5\% of those undergoing diode laser treatment versus $0.0 \%$ undergoing TURP. ${ }^{14}$

The current study revealed higher complication rates in the diode laser group but no significant differences among the three groups $(P=0.237)$. Additionally, there were no reports of TURP syndrome among patients in any group. The blood-loss-requiring-blood-transfusion rate has been reported as $0.0 \%-2.2 \%{ }^{14}$ In our study, blood transfusion was required in one patient undergoing PVP treatment. In previous reviews of early complications, $1.1 \%$ of patients required re-catheterization. ${ }^{15,16}$ Reported reoperation rates have been lower than $2.2 \% .{ }^{17,18}$ In the current study, no statistically significant differences were observed between these three groups.

As far as we are aware, this is the first study to outline the differences between laser prostatectomy techniques in terms of handling and operative outcome. This paper has provided necessary information to help urologists differentiate between laser systems and critically evaluate the role of these techniques in the treatment of LUTS due to BPH.

\section{Conclusion}

Laser prostatectomy is increasingly being considered as a valid clinical alternative to TURP. This study compared the efficacy of three laser techniques used to treat LUTS due to BPH. PVP, a coagulation-based technique, has durable efficacy for prostates weighing $<60 \mathrm{~g}$. Tm laser (an enucleation laser technique) has previously been criticized for having a steep learning curve due to the fact that this laser requires a certain volume of enucleated tissue. Nonetheless, our evidence supports the contention that Tm offers favorable and durable outcomes for prostates of any size and low morbidity rates, both early and late. GreenLight HPS laser prostatectomy has been more widely accepted and offers favorable outcomes for prostates weighing $<60 \mathrm{~g}$. Diode laser prostatectomy (a coagulation-based technique) is preferred for prostates weighing $>60 \mathrm{~g}$ and among patients with thrombocytopenia or who have a tendency for bleeding.

In our study, these techniques were found to be equally safe and effective in the treatment of BPH without any severe drawbacks as long as patients were selected according to risk factors. However, future research should use higher quality data to further evaluate and compare types of laser treatment to confirm our results.

\section{Disclosure}

The authors declare no conflicts of interest in this work.

\section{References}

1. Wasson JH, Reda DJ, Bruskewitz RC, Elinson J, Keller AM, Henderson WG. A comparison of transurethral surgery with watchful waiting for moderate symptoms of benign prostatic hyperplasia. The Veterans Affairs Cooperative Study Group on Transurethral Resection of the Prostate. N Engl J Med. 1995;332(2):75-79.

2. Gravas $\mathrm{S}$, Bachmann $\mathrm{A}$, Reich $\mathrm{O}$, et al. Critical review of lasers in benign prostatic hyperplasia (BPH). BJU Int. 2011;107(7):1030-1043.

3. Rieken M, Ebinger Mundorff N, Bonkat G, Wyler S, Bachmann A. Complications of laser prostatectomy: a review of recent data. World J Urol. 2010;28(1):53-62.

4. Reich O, Bachmann A, Siebels M, Hofstetter A, Stief CG, Sulser T. High power $(80 \mathrm{~W})$ potassium-titanyl-phosphate laser vaporization of the prostate in 66 high risk patients. $J$ Urol. 2005;173(1):158-160.

5. Elzayat E, Habib E, Elhilali M. Holmium laser enucleation of the prostate: a size-independent new "gold standard". Urology. 2005; 66(Suppl 5):108-113.

6. Shao IH, Hou CP, Chen SM, et al. The safety and efficacy of aspirin intake in photoselective vaporization laser treatment of benign prostate hyperplasia. Clin Interv Aging. 2013;8:265-269.

7. Elmansy H, Baazeem A, Kotb A, et al. Holmium laser enucleation versus photoselective vaporization for prostatic adenoma greater than $60 \mathrm{~mL}$ : preliminary results of a prospective, randomized clinical trial. J Urol. 2012;188(1):216-221.

8. Madersbacher S, Alivizatos G, Nordling J, Sanz CR, Emberton M, de la Rosette JJ. EAU 2004 guidelines on assessment, therapy and follow-up of men with lower urinary tract symptoms suggestive of benign prostatic obstruction (BPH guidelines). Eur Urol. 2004;46(5): $547-554$.

9. Rassweiler J, Teber D, Kuntz R, Hofmann R. Complications of transurethral resection of the prostate (TURP) - incidence, management, and prevention. Eur Urol. 2006;50(5):969-979; discussion 980.

10. Taylor K, Filgate R, Guo DY, Macneil F. A retrospective study to assess the morbidity associated with transurethral prostatectomy in patients on antiplatelet or anticoagulant drugs. BJU Int. 2011;108 Suppl 2: $45-50$.

11. Descazeaud A, Robert G, Azzousi AR, et al; Committee for lower urinary tract symptoms of the French Association of Urology. Laser treatment of benign prostatic hyperplasia in patients on oral anticoagulant therapy: a review. BJU Int. 2009;103(9): $1162-1165$.

12. Erol A, Cam K, Tekin A, Memik O, Coban S, Ozer Y. High power diode laser vaporization of the prostate: preliminary results for benign prostatic hyperplasia. J Urol. 2009;182(3):1078-1082.

13. Seitz M, Sroka R, Gratzke C, et al. The diode laser: a novel side-firing approach for laser vaporisation of the human prostate - immediate efficacy and 1-year follow-up. Eur Urol. 2007;52(6):1717-1722.

14. Rieken M, Wyler S, Müller G, et al. 589 laser vaporization of the prostate: intermediate-term follow-up with the $200 \mathrm{~W}$ high-intensity diode (HIDI) laser system. Eur Urol Suppl. 2009;8(4):268. 
15. Capitán C, Blázquez C, Martin MD, Hernández V, de la Peña E, Llorente C. GreenLight HPS 120-W laser vaporization versus transurethral resection of the prostate for the treatment of lower urinary tract symptoms due to benign prostatic hyperplasia: a randomized clinical trial with 2-year follow-up. Eur Urol. 2011;60(4):734-739.

16. Bach T, Herrmann TR, Haecker A, Michel MS, Gross A. Thulium:yttriumaluminium-garnet laser prostatectomy in men with refractory urinary retention. BJU Int. 2009;104(3):361-364.
17. BachT, Wendt-Nordahl G, Michel MS, HerrmannTR, Gross AJ. Feasibility and efficacy of Thulium:YAG laser enucleation (VapoEnucleation) of the prostate. World J Urol. 2009;27(4):541-545.

18. Bach T, Netsch C, Haecker A, Michel MS, Herrmann TR, Gross AJ. Thulium:YAG laser enucleation (VapoEnucleation) of the prostate: safety and durability during intermediate-term follow-up. World J Urol. 2010;28(1):39-43.

\section{Publish your work in this journal}

Clinical Interventions in Aging is an international, peer-reviewed journal focusing on evidence-based reports on the value or lack thereof of treatments intended to prevent or delay the onset of maladaptive correlates of aging in human beings. This journal is indexed on PubMed Central, MedLine, the American Chemical Society's 'Chemical Abstracts Ser- vice' (CAS), Scopus and the Elsevier Bibliographic databases. The manuscript management system is completely online and includes a very quick and fair peer-review system, which is all easy to use. Visit http://www.dovepress.com/testimonials.php to read real quotes from published authors.

Submit your manuscript here: http://www.dovepress.com/clinical-interventions-in-aging-journal 